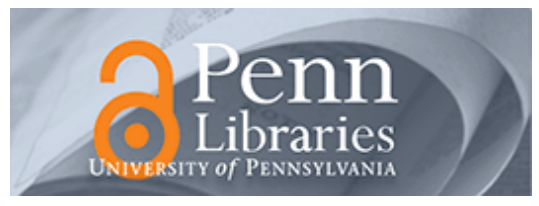

University of Pennsylvania

ScholarlyCommons

Finance Papers

Wharton Faculty Research

2000

\title{
The Relation Between Stock Market Movements and NYSE Seat Prices
}

Donald B. Keim

University of Pennsylvania

Ananth Madhavan

Follow this and additional works at: https://repository.upenn.edu/fnce_papers

Part of the Finance Commons, and the Finance and Financial Management Commons

Recommended Citation

Keim, D. B., \& Madhavan, A. (2000). The Relation Between Stock Market Movements and NYSE Seat

Prices. The Journal of Finance, 55 (6), 2817-2840. http://dx.doi.org/10.1111/0022-1082.00308

This paper is posted at ScholarlyCommons. https://repository.upenn.edu/fnce_papers/301

For more information, please contact repository@pobox.upenn.edu. 


\title{
The Relation Between Stock Market Movements and NYSE Seat Prices
}

\begin{abstract}
Exchange seat prices are widely reported and followed as measures of market sentiment. This paper analyzes the information content of NYSE seat prices using: (1) annual seat prices from 1869 to 1998 , and (2) the complete record of trades, bids and offers for the seat market from 1973 to 1994. Seat market volumes have predictive power regarding future stock market returns, consistent with a model where seat market activity is a proxy for unobserved factors affecting expected returns. We find abnormally large price movements in seats prior to October 1987, consistent with the hypothesis that seat prices capture market sentiment.
\end{abstract}

Disciplines

Finance | Finance and Financial Management 


\title{
The Relation Between Stock Market Movements and NYSE Seat Prices
}

\author{
Donald B. Keim and Ananth Madhavan*
}

November 4, 1999

Keim is from Wharton School, University of Pennsylvania and Madhavan is from Marshall School of Business, University of Southern California. We thank René Stulz (editor) for many helpful suggestions that greatly improved the paper. We are also grateful for comments on earlier incarnations of this paper from Yakov Amihud, Lawrence Harris, Nicholas Kiefer, Bruce Lehmann, Lubos Pastor, G. William Schwert, George Sofianos, Avi Wohl, and seminar participants at Berkeley, Cambridge University, New York University, Riverside, University of Southern California, the Econometric Society Meetings, the JFI Conference, and the University of California at Davis Conference "Ten Years After the Crash." Yuval Bar-Or, Marshall Gordon, and Jason Yacoub provided expert research assistance. Keim thanks the Rodney White Center for financial assistance. Any errors are our own. 


\title{
The Relation Between Stock Market Movements and NYSE Seat Prices
}

\begin{abstract}
Exchange seat prices are widely reported and followed as measures of market sentiment. This paper analyzes the information content of NYSE seat prices using: (1) Annual seat prices from 1869 to 1998, and (2) The complete record of trades, bids and offers for the seat market from 1973 to 1994 . Seat market volumes have predictive power regarding future stock market returns, consistent with a model where seat market activity is a proxy for unobserved factors affecting expected returns. We find abnormally large price movements in seats prior to October 1987, consistent with the hypothesis that seat prices capture market sentiment.
\end{abstract}


As capital assets whose prices reflect the expectations of the market participants with the most intimate contact with the trading process, exchange seats are of considerable interest to financial economists and practitioners. Seat prices are widely reported and followed as measures of market sentiment and health. Press accounts pay special emphasis to unusually high or low transaction prices, often implying that seat price changes anticipate overall market movements. Academic research, however, has failed to find such a relation. Schwert (1977a), in a seminal study, analyzes monthly seat returns in the period from 1926 to 1972 and shows that seats have the characteristics of capital assets, but finds no evidence that seat returns predict market returns. Seat prices are also of interest because they reflect the impact of competitive and regulatory factors on security markets (see, e.g., Doede (1967), Schwert (1977b), Stoll (1979), Jarrell (1984), Chiang, Gay, and Kolb (1987), Ip and Lohse (1998), Bagnoli and Battalio (1996), and Arnold, Hersch, Mulherin, and Netter (1999)).

This paper examines the information content of transactions and quotes for New York Stock Exchange (NYSE) seats. We develop a model that explains how seat market activity is informative about factors affecting overall market returns and examine this hypothesis empirically using two unique datasets: (1) Annual seat prices from 1869 to 1998, and (2) The complete intradaily record of trades, bids and offers for the seat market from 1973 to 1994.

Our analysis yields several new results. Although exchange seat returns have no predictive power (confirming Schwert's (1977a) result), seat market activity does capture important information about future stock market returns. Specifically, lagged innovations of trading volumes in the seat market significantly predict the monthly excess returns of the S\&P 500 after controlling for variables such as the dividend yield and book-to-market ratio that are found to display predictive power in other studies. Similar results apply to other measures of seat market liquidity including changes in the quoted bid-ask spread for seats. These results are consistent with a model where seat market liquidity is a proxy for factors - such as future stock market volatility affecting expected returns. We document a permanent (information) component to seat transactions, again consistent with the view that seat trades are regarded as informative.

Our long-horizon data also provide insights into the value of the exchange franchise over time. Although in nominal terms seat prices today are at all-time highs, in real terms they are roughly at the same level now as they were at the beginning of the century. Seat prices, however, exhibit sharp price movements that require further analysis. Accordingly, we estimate a model of 
monthly seat returns, finding added confirmation for Schwert's view that seat returns are determined like those of other capital assets. We use the model to compute abnormal returns prior to the Crash of October 1987. We find large positive abnormal returns to seats in the 12 months prior to October 1987 followed by large negative abnormal returns, a pattern that closely resembles the Crash of 1929. These findings are consistent with a behavioral interpretation where seats (as capital assets that cannot be short sold, are in limited supply, and whose values are tied to asset price levels) exhibit occasional price bubbles. In summary, seat transactions are informative, but the nature of this signal is subtle and complex, reflecting elements of both predictable risk exposure and occasional market sentiment.

The paper proceeds as follows: Section I provides a model of seat prices that guides our subsequent empirical analyses; Section II describes our data and relevant institutional details; Section III analyzes the return and risk characteristics of seat prices; Section IV investigates the information contained in seat price transactions and volume, focusing on the ability of seat market variables to predict market returns; Section V concludes the paper.

\section{Theoretical Considerations}

\section{A. A Model of Seat Market Activity}

We begin by developing a theoretical model to identify seat market variables that might be useful in forecasting future stock market returns. The model's objective is not only to provide an explanation for why these variables might have predictive power in an efficient market but also to reconcile this explanation with the fact (Schwert (1977a)) that seat price movements do not predict stock market returns.

Seats have value because they provide their owners with future cash flows from their

presence on the floor. ${ }^{2}$ First consider the set of existing seatholders. Let $C\left(\sigma_{\mathrm{t}}, h_{\mathrm{it}}\right)$ denote the cash flow to a floor broker $i$ at the end of period $t$ as a function of a market-wide state variable, denoted by $\sigma_{\mathrm{t}}$, and its owner's human capital, $h_{\mathrm{it}}$. The variables $\sigma_{\mathrm{t}}$ and $h_{i t}$ are interpreted broadly; $\sigma_{\mathrm{t}}$ is a proxy for market-wide illiquidity or stress (volatility) while $h_{i t}$ measures trading skill. Higher values of $\sigma$ imply greater risk and hence higher market returns in the future as compensation for bearing this risk, as in Merton (1980). B Human capital takes on one of two values $\left\{h_{1}\right.$, $\left.h_{2}\right\}$, where $h_{1}<h_{2}$. Denote the number of existing seatholders (excluding new entrants) in human capital class $k$ at time $t$ as $N_{\mathrm{kt}}$. Existing brokers transition among states according to a sta- 
tionary transition matrix $\mathbf{P}=\underbrace{p}_{q)}(1-p)$ trading skills (i.e., $h_{1} \rightarrow h_{2}$ ) while successful brokers may "burn out" or trade less efficiently (i.e., $\left.h_{2} \rightarrow h_{1}\right)$. Skill levels are relatively stable so $p, q \in(1 / 2,1)$. Barring entry and exit, it is easy to show that the long-run proportions of brokers in skill categories $h_{1}$ and $h_{2}$ are, respectively, (1$q) /[(1-p)+(1-q)]$ and $(1-p) /[(1-p)+(1-q)]$.

Higher trading ability enables seatholders to earn more profits, and we model cash flows as $C\left(\sigma_{\mathrm{t}}, h_{\mathrm{it}}\right)=c\left(\sigma_{\mathrm{t}}\right) h_{\mathrm{it}}$, where $c(\sigma)$ is a continuous function of the state. While we would generally expect commission revenues to decrease with $\sigma$, the function $c(\sigma)$ need not be monotonic in $\sigma$. Previous research (Keim and Madhavan (1997)) shows that common stock trades can vary considerably in degree of difficulty, i.e., in dimensions such as order size and aggressiveness, so that commission revenue depends on the composition of trading volume. In states with very low volatility, market liquidity may be very high and traders can execute relatively large trades with minimal price impacts. In this case, the fraction of volume directed to brokers to be "worked" on the floor, and consequently commission revenues, can be low. As volatility increases, more difficult orders may be directed to floor traders, increasing their commission revenue. For very high states of volatility, however, volumes may be negligible and commission revenues may fall sharply. To allow for such possibilities, we do not impose any a priori restrictions on the functional form of $c(\sigma)$.

In every period $t$, the market state variable $\sigma_{\mathrm{t}}$ is the realization of an independently and identically distributed random variable. The state's current value is observed by all agents in the model (although not by the econometrician) but future values are unknown. For a seatholder with human capital skills $h_{\mathrm{i}}(i=1,2)$ at time $t$ the expected present value of the cash flows from seat ownership is

$$
v_{i, t}=E \underbrace{\infty}_{k} \frac{c\left(\sigma_{t+k}\right) h_{i, t+k}}{(1+r)^{k}} \bigotimes_{\frac{h_{i t}}{c}\left(\sigma_{t}\right)}+\Pi_{i}
$$

where $r$ is the discount rate and $\Pi_{\mathrm{i}}$ represents the expected present value of all cash flows from date $t+1$ on, where the expectation is taken over possible future realizations of the state and human capital. Given the assumed structure of the transition matrix $\mathbf{P}$ it is easy to show that $\Pi_{1}<$ $\Pi_{2}$. In other words, since brokers tend to remain in their skill category, the expected future 
earnings of a low skill broker is below that of a high skill broker. From equation (1) the lowest reservation price is held by brokers with the least human capital, i.e., $v_{1, t}=h_{1} c\left(\sigma_{t}\right)(1+r)^{-1}+\Pi_{1}$,

Now consider a potential buyer $j$ drawn from a set of $J$ potential risk-neutral entrants. Entrants are drawn each period from a pool of potential entrants and do not know their trading ability prior to entry. Immediately upon entry at time $t$, a new seatholder has the lowest skill level so that $h_{\mathrm{jt}}=h_{1}$. After one period in the market (in period $t+1$ ), an entrant's true skill level is revealed according to a stationary probability distribution, and thereafter (periods $t+2$ etc.) the entrant is an established seatholder whose abilities evolve according the transition matrix $\mathbf{P}$, as above. 1 We assume the probabilities that a new entrant is of type $h_{1}$ or $h_{2}$ are the same as those for the population as a whole, i.e., $(1-q) /[(1-p)+(1-q)]$ and $(1-p) /[(1-p)+(1-q)]$. The probability of the new seatholder being in category $h_{2}$ in period $t+1$ is $\operatorname{Pr}\left[h_{\mathrm{j} t+1}=h_{2}\right]=(1-p) /[(1-p)+(1-q)]$. Recall that the probability of an existing seatholder (not a new entrant) moving from skill level $h_{1}$ to $h_{2}$ in period $t+1$ is simply $1-p<(1-p) /[(1-p)+(1-q)]$. Thus, a new entrant has a better chance of becoming a skilled broker than an existing broker with a low skill level.

For an entrant, the reservation price at time $t$ is the expected present value of cash flows less the entry costs to floor trading. Entry costs consist of the direct costs of establishing a physical presence on the floor and associated back office costs and, perhaps more importantly, implicit costs (including the costs of building reputational capital with other floor participants) associated with floor trading. Let $\Psi\left(\sigma_{\mathrm{t}}\right)>0$ denote the cost of entry at time $t$, which we presume is strictly increasing in $\sigma_{\mathrm{t}}$, the state variable. This is intuitive since in times of market stress the purchase of a seat entails greater risk and hence higher financing costs. Further, the acquisition of reputational capital may be more difficult when market volatility is high. Denote by $V_{\mathrm{j}, \mathrm{t}}$ the reservation price of entrant $j$, so that at time $t$

$$
V_{j, t}=E \underbrace{\infty}_{k} \frac{c\left(\sigma_{t+k}\right) h_{j, t+k}}{(1+r)^{k}} \mathcal{Q} \Psi\left(\sigma_{t}\right)=\frac{h_{1} c\left(\sigma_{t}\right)}{(1+r)}+\Pi_{e}-\Psi\left(\sigma_{t}\right),
$$

where $\Pi_{\mathrm{e}}$ represents the expected future cash flows. Note that $\Pi$ lies between the high and low skill state skill levels because the new entrant's chances of being high skilled exceed those of an existing low skilled broker. Under our simplifying assumptions, potential entrants share a common value at time $t$, denoted by $V_{\mathrm{t}}$.

\section{A.1 Trading and Volume}


Define a function $g(\sigma)=\left(\Pi_{e}-\Pi_{1}\right)-\Psi(\sigma)$ that represents the difference between the valuations of potential entrants and the class of seatholders who place the lowest value on their seats. Let $\sigma^{*}$ be the value of the state variable for which $\mathrm{g}(\sigma)=0$, i.e., when outsiders have reservation prices equal to those of the most eager potential sellers. The function $\mathrm{g}(\sigma)$ is strictly $d e$ creasing so that for $\sigma>\sigma^{*}$ there are no mutually beneficial opportunities for trade. At the start of time $t$, nature selects the state variable $\sigma_{\mathrm{t}}$ and this realization is observed by all agents. One of two possible states may occur: (1) If $\sigma_{\mathrm{t}}>\sigma^{*}$ then $V_{\mathrm{t}}<v_{1 \mathrm{t}}$, i.e., the reservation price of a potential buyer is below that of the most eager seller, and no trade occurs, or (2) Conversely, if $\sigma_{\mathrm{t}}<\sigma^{*}$ then $V_{\mathrm{t}}>v_{1 \mathrm{t}}$ (under our assumptions $v_{2 \mathrm{t}}>V_{\mathrm{t}}$ ) and there are mutually advantageous gains from trade if $N_{1 \mathrm{t}}>0$. This occurs with positive probability. Without modeling the exact details of the bargaining process, we assume that if there are mutually beneficial opportunities for exchange then trade will occur. Thus, the volume of trade in period $t$ in the second case is $N_{1 \mathrm{t}}$. It follows immediately that trading activity in the seat market is inversely related to the expected overall market volatility. Merton (1980) shows that higher expected volatility can be associated with a larger risk premium and hence we would expect an inverse relation between seat market activity and future returns.

\section{A.2. Other Proxies: Quoted Spreads and Returns}

Note that the quoted bid-ask spread for seats is also a proxy for the state variable because it is inversely related to trading activity in the seat market. When $\sigma_{\mathrm{t}}>\sigma^{*}$, the ask price is set by competition among potential sellers at $v_{1 \mathrm{t}}$ while the bid price is determined by competition among potential buyers at $V_{\mathrm{t}}$ and the average spread is $s\left(\sigma_{t}\right)=\Psi(\sigma)-\left(\Pi_{e}-\Pi_{1}\right)>0$. When $\sigma_{\mathrm{t}}$ $<\sigma^{*}$, the spread is by definition zero when buyers and sellers agree on a price to trade.

Seat price returns, however, can provide misleading inferences about changes in the state variable. In particular, observe that if a trade occurs, the transaction price, denoted $P_{\mathrm{t}}$, can be expressed as $P_{t}=\alpha_{t} v_{1 t}+\left(1-\alpha_{t}\right) V_{t}$ where $\alpha_{t} \in(0,1)$ captures the ability of buyers to negotiate a more favorable price. Seat price movements thus reflect changes in bargaining ability $\alpha_{\mathrm{t}}$ (which may be related to $\sigma$ in unknown ways) and in the mean valuation $\left(v_{1 t}+V_{t}\right) / 2$. We do not model the bargaining process but it is possible that there is a systematic tendency for transactions to occur at one or the other side of the market based on $\sigma$, confounding inferences drawn using seat 
returns. Even if we can correctly isolate changes in the mean valuation (say using midquote returns), making inferences about changes in $\sigma$ are problematic because the function $\mathrm{c}(\sigma)$ (which underlies both valuations) may be non-monotonic. Thus, an increase in $\sigma$ need not necessarily imply a decrease in seat prices, depending on its effect on the composition of volume.

\section{B. Sentiment}

Many market participants have noted the propensity of seat prices to respond in an exaggerated manner to market movements (Roeder (1999)), and seat prices are often regarded as measures of sentiment (McGee (1998)). Indeed, seats are unique in several respects that are relevant in this context. As noted by Schwert (1977a) they are capital assets whose values reflect expectations of future market activity and returns, they are in fixed supply, and they cannot readily be sold short.

Recent work in behavioral finance has shown that agents place too much weight on near term events, especially extreme events. If this observation applies to the seat market, traders might be excessively optimistic (pessimistic) about seat cash flows following unexpectedly large increases (decreases) in stock prices. In the latter case, however, the prices of seats need not be biased (relative to a rational forecast) because outsiders can freely buy them from pessimistic sellers, provided the market also contains large numbers of risk neutral agents with correct expectations. In the case of good news this is not the case because seats cannot be sold short.

This argument suggests an interesting test of whether the seat market reflects sentiment: examine the pattern of excess returns to seats relative to a suitable factor model associated with large stock market increases. A series of abnormally positive returns would indicate an exaggerated reaction to stock market movements that is consistent with the type of behavior posited by commentators, possibly justifying some of the interest in the seat market.

\section{Institutions and Data}

\section{A. Institutional Details}

The New York Stock Exchange (NYSE) is a New York State not-for-profit organization whose net assets are owned by its seatholders. ${ }^{6}$ Ownership of a NYSE seat confers full distributive rights in the NYSE's net assets, and allows a member access to the NYSE's trading floor. Should the NYSE de-mutualize (i.e., sell shares to the public), seat holders would be residual claimants to the organization's assets. The NYSE was founded in 1792, and seat transactions 
were first allowed in 1869. There are 1,366 regular members who own seats. ${ }^{\square}$ Seats are indivisible, implying that the supply of seats in the last four decades has been fixed.

Seats have value because they entitle their owners to buy and sell securities on the floor, either as an agent for others or for their own account. Members can participate in trading in several different roles, including: (1) Specialists, who are exchange-designated market makers, responsible for providing liquidity and maintaining price continuity in their assigned NYSE-listed stocks, (2) Commission (house) brokers, who help execute orders for brokerage firms, (3) Independent (Two-dollar) brokers who handle the trades of other members, (4) Floor traders, who trade for their personal accounts, and (5) Registered Competitive Market Makers, who are independent floor traders with additional affirmative obligations to provide liquidity. Specialists and brokers (house and independent) represent the largest categories on the floor, accounting for 35 percent and 61 percent of total members, respectively. The member determines how the seat is used and in this sense, seats are undifferentiated products. For example, although every specialist must own a seat, there is no such thing as a "specialist seat." Before 1978 seats could not be leased to others, but leasing is now relatively common.

Seats are traded in an auction market maintained by the Secretary of the NYSE. Current bid and ask quotes are posted in prominent locations on the floor of the exchange, and there are no transaction costs to purchasing or selling a seat. In theory, the market for NYSE seats is a continuous market because transactions or quote changes can be made at any time during the day. In practice, however, seats are thinly traded and quotes can remain in effect for several days. The seat market is a particularly simple example of a limit order book system, a trading design that is increasingly common in financial markets.

Not all transactions take place in the auction market. Private sales or transfers between individuals within the same member institution could potentially involve consideration other than cash and for this reason need not occur at or within the quoted bid and offer prices. For this reason, we focus only on public seat transactions in cash.

\section{B. Data Sources and Procedures \\ B.1 Trade and Quote Data}

Our analysis is based on a complete chronological record of all bids, offers, and transactions in the NYSE seat market from January 1973 to July 1994 . 8 These data are unique in several important respects. First, although transactions are infrequent, quotations are available on a daily 
(and occasionally intradaily) basis. Quotation data are interesting because they can be used to measure the range of estimates of seat value by market participants. To our knowledge, these data have not been examined before. Second, the data identify the date and time (to the nearest minute) of all quotes and transactions, allowing us to investigate in more detail the relation between seat prices and future stock market returns and activity. Previous studies use prices for transactions that occur closest to the end of the month. Such prices present potential problems because the exact dates of the transactions (or the changes in bids or offers that lead to a transaction) are not observed.

Third, the data identify the trader behind the quoted bid and ask and the parties to a transaction. This information, together with quotation data, and descriptors such as "X sells to Y" aid in the identification of trade initiation. Fourth, the data also provide information on the nature of the sale. Most importantly, they identify whether the seat price includes option trading rights and whether the sale is public or is a private sale or transfer. This information helps us identify and exclude trades (e.g., private sales or transfers) taking place at non-market prices. Finally, the period from 1973 to 1994 is of particular interest as it covers several events that pertain to the competitive position of the NYSE and the profitability of the brokerage industry. These events include the elimination of fixed commissions in May 1975, the introduction of the DOT electronic trading system in March 1976, the introduction of the Intermarket Trading System (ITS) in April 1978, and the Crash of October 1987.

The data are obtained from the NYSE in the form of a hand-written ledger and are then

transcribed by hand to electronic form. ${ }^{0}$ Several filters are used to ensure the accuracy of the data. First, we screen the data for obvious outliers and other keypunch errors such as dropped digits. Second, we cross-check the transaction prices against reported prices available through other sources (e.g., the NYSE Fact Book). Finally, we take care to ensure that sequences of transaction prices are comparable by excluding private sales and transfers, and by correcting for the effect of option trading rights which can be traded separately.

To illustrate the nature of the data, consider Table I. The table shows the quotation record from Monday, July 21 to Wednesday, July 23, 1986, with only the first initial of the participants' last names used to preserve anonymity. At the open of the auction market at 9:00 on Monday, the bid and ask prices were $\$ 505,000$ and $\$ 600,000$ (based on quotes by $\mathrm{S}$ and $\mathrm{W}$ ), respectively. These quotes remained in effect through the open on Tuesday. At 11:15, an outside 
investor, T who was not previously represented on either the bid or ask side, hit the quoted bid and sold to $\mathrm{S}$ at the bid price of $\$ 505,000$. With $\mathrm{S}$ out of the market, the best bid was represented by $\mathrm{G}$ for $\$ 410,000$. This bidder then improved the bid to $\$ 430,000$ at 13:00, and at 13:30 on Tuesday, a new player L entered the market and posted an ask price of $\$ 550,000$. At 14:20, a new bidder $\mathrm{B}$ entered with a bid of $\$ 435,000$. These quotes remained in effect until 10:40 on Wednesday, when yet another new player A improved the bid further to $\$ 450,000$. This offer was quickly countered by $\mathrm{B}$, who improved the bid to $\$ 460,000$. These quotes remained in effect for the rest of the week.

This example serves to illustrate several aspects of the data. First, quotes narrow in response to new trading interest as shown by the quote records for Wednesday, July 23. Second, although the trade shown here is seller-initiated, traders often adjust their quotes to signal their willingness to trade. This is illustrated by the quote record for 13:00 on Tuesday, July 22, when $\mathrm{G}$ voluntarily raises his bid price from $\$ 410,000$ to $\$ 430,000$, possibly to indicate an active interest in trading. The variability of the quoted bid-ask spread makes it difficult to use this measure as a proxy for seat market liquidity. Third, the transaction in this example is viewed as informative in the sense it has a permanent effect on the seat price level. Indeed, the price change from the pre-trade midquote to the opening midquote the day after the seat sale is -10.8 percent.

Most days feature less activity. Overall, there are 686 trades in the sample period, implying a trading frequency of just 0.20 per business day. In contrast, the quotation frequency is much higher with an average of two quotations per business day over the entire period. Both trading and quotation frequencies are higher in the 1973 to 1980 period which includes events such as the elimination of fixed commissions, the oil crisis, and a major recession. Of particular interest, the mean percentage pre-trade bid-ask spread is large, 22.54 percent.

\section{B.2. Annual Data}

We obtain from the NYSE an annual series of seat prices covering the period from 1869 , when trading in seats commenced, through year-end 1998. The long-horizon data provide a useful historical perspective that helps place our more detailed transaction-level analyses in context. However, the annual series includes high and low seat prices in each year, and the nonsynchronous nature of the data warrant some caution when interpreting the results. As noted by Working (1960) and Schwert (1990), averaging high and low prices within the year produces time series characteristics that are similar to those that result when time-averaging data that come 
from a random walk. The returns from such a series resemble a first-order moving average with correspondingly high first-order autocorrelation and understated standard deviations. Schwert (1990) employs a procedure to correct for this effect when he constructs a market return series (that we use below) based on the Cowles Index (which averages high and low prices). The summary statistics that we report below reflect this correction.

\section{Risk and Return Characteristics of Exchange Seats}

\section{A. Seats as Capital Assets}

We begin by examining the risk and return characteristics of seats, viewing them as capital assets. The mean annual return (standard deviation) for the 1869 to 1998 period is 8.07 percent (28.1 percent) for exchange seats and 10.73 percent (18.45 percent) for the entire market. 10

Similar results hold for monthly data in the period from 1973 to 1994. These aggregate figures conceal considerable variation over time, necessitating a more formal analysis of the relation between risk and return for exchange seats. We use a model first proposed by Schwert (1977a) for this purpose.

We extend Schwert's original analysis in two ways: (1) We update the sample period using detailed transaction-level data from 1973 to 1994; and (2) We include additional independent variables in the model to control for other factors affecting seat returns. To capture the influence of trade activity, we include the log monthly change in composite NYSE volume. Fama and French (1993) argue that two additional factors are useful to capture the nondiversifiable risk of an asset. They find that a size-related and a value/growth-related factor are helpful in describing asset return variation. We therefore include those two factors in our model.

We estimate the following regression model:

$$
R_{t}-r_{f, t}=\alpha+\sum_{i=0}^{k} \beta_{i}\left(r_{m, t-i}-r_{f, t-i}\right)+\sum_{i=0}^{k} \gamma_{i} S M B_{t-i}+\sum_{i=0}^{k} \delta_{i} H M L_{t-i}+\sum_{i=0}^{k} \phi_{i} V O L_{t-i}+\varepsilon_{t},
$$

where $R_{\mathrm{t}}$ is the return on NYSE seats in month $t, r_{\mathrm{f}, \mathrm{t}}$ is the treasury bill rate, $r_{\mathrm{m}, \mathrm{t}}$ is the return on a value-weighted market index, $S M B_{\mathrm{t}}$ is a monthly size premium (small stock return - large stock return), $H M L_{\mathrm{t}}$ is a monthly book/market premium (high $\mathrm{B} / \mathrm{M}$ return - low $\mathrm{B} / \mathrm{M}$ return), $V O L_{\mathrm{t}}$ is the (logarithmic) growth in the aggregate NYSE share volume from month $t-1$ to month $t$, and $\varepsilon_{\mathrm{t}}$ is the error term. The first three factors are those used by Fama and French (1993). 
The results for the entire sample and two subperiods for $k=1$ are summarized in Table II. Results for other lags are similar and are not reported here. For the entire period, contemporaneous excess market returns are positive $(p$-value $=0.06)$, but well below one, indicating that seat prices respond to market information, albeit slowly. The sensitivity of seat prices to market movements appears to have increased over the sample period; in the post-1984 period the coefficient on the market return is 0.55 and statistically significant at the 5 percent level. The two factors used by Fama and French (1993) vary in their significance across the subperiods. The coefficient on the size premium is significant in the entire period and in the pre-1985 period but not in the most recent subperiod. This factor, which has been shown to have a significant effect on stock returns, thus also affects seat returns perhaps reflecting the illiquid nature of both the market for seats and for small-cap stocks in the earlier sample. The lagged value of this variable also follows a similar pattern, but the value-growth factor has little explanatory power. Finally, there is a significant relation between monthly seat price changes and contemporaneous monthly NYSE volume changes in the overall period, but lagged volume has little explanatory power.

\section{Predictability of Returns}

\section{A. Return Predictability Using Monthly Data}

Our model suggests that variables associated with seat market liquidity (transaction frequency and the bid-ask spread) are related to expectations about future market volatility. Merton (1980) shows that the equilibrium expected return for the market is an increasing function of the risk of the market, and argues that models of the market risk premium must account for changes in the level of market risk. He goes on to suggest that the model can be improved by inclusion of additional non-market instruments for market risk, such as surveys of investor expectations. Seat market activity represents a market-determined observation on such expectations, and we expect changes in lagged seat activity to, likewise, have predictive power.

\section{A.1. Correlations Among Seat Market Variables}

As a convenient way of summarizing the relation between seat market variables and market returns and volatility, we show in Table III the matrix of estimated Pearson correlation coefficients among the variables. A correlation coefficient $\rho$ whose absolute value is statistically significant under the null hypothesis $\mathrm{H}_{0}: \rho=0$ is indicated with an asterisk. The variables of interest are (for month $t$ ) the current and next month's excess return on the S\&P 500 index, market 
volatility (measured by the absolute excess return of the S\&P 500 index), the excess return on seats, the average bid-ask spread (expressed as a percentage of the midquote price) in the seat market, the number of transactions (volume) in the seat market, and the signed order flow in the seat market. We define order flow as $X_{t}=\sum_{i=1}^{N_{t}} z_{i, t}$ where $z_{\mathrm{i}, \mathrm{t}}$ is a trade-initiation variable for trade $i$ in month $t(z=+1$ for a buyer-initiated trade, $z=-1$ for a seller initiated trade, and $z=0$ for a trade at the midquote).

The results in Table III are interesting in several respects. First, observe that the only variable that is significantly correlated with future stock market excess returns is the volume of seat trades. This correlation is negative and significant at the 5 percent level, consistent with the prediction of our model. Trading activity in the seat market is also negatively related to current stock market returns and this correlation is statistically significant at the 10 percent level. Trading activity is also positively and significantly correlated with overall market volatility, again the only variable to do so in a significant manner. ${ }^{13}$ Second, although seat returns are correlated with contemporaneous market returns, over the period from 1973 to 1994 the correlation with future stock market returns is not significantly different from zero. This is consistent with Schwert (1977a) for the period ending in 1973. Third, the order flow variable is positively and significantly correlated with contemporaneous stock market returns. Since there are entry costs, the decision to trade a seat is likely to have been made some time prior to the actual trade, so that this result suggests that seat order flow is related to signals about future stock market movements. Seat market returns are positively and significantly correlated with contemporaneous signed order flow in the seat market, consistent with Table I where trade initiation affects the seat price level. Fourth, trading activity in the seat market is also negatively related to current stock market returns and this correlation is statistically significant at the 10 percent level. Finally, as we would expect, seat volumes are negatively and significantly related to the contemporaneous seat bid-ask spread. We turn now to a more formal investigation of the predictive power of seat market variables.

\section{A.2. Regression Models}

Recent research finds similar patterns of predictability in stock returns. For example, Fama and Schwert (1977), Campbell (1987) and Keim and Stambaugh (1986) use ex ante observable market variables that capture the level of treasury bill yields, asset prices, default pre- 
mium, and the term structure slope to predict monthly stock and bond returns. Fama and French (1988) and Harvey (1991) use the dividend yield for the U.S. equity market to predict stock returns domestically and internationally, respectively. Kothari and Shanken (1997) and Pontiff and Schall (1998) use the book-to-market ratio for the overall market to predict stock returns.

Our model suggests that liquidity in the seat market may proxy for unobserved factors affecting expected returns. Seat market liquidity (as measured by volume) is likely to be autocorrelated so we focus on the innovation in the liquidity variable. In addition to lagged seat market volumes, we also include as controls the seat price level (a proxy for entry barriers), the change in the seat bid-ask spread (a proxy for transactions costs), and the lagged absolute seat return (a proxy for risk). We model transaction activity as:

$$
N_{t}=\beta_{0}+\sum_{i=1}^{6} \beta_{i} N_{t-i}+\lambda_{1} \text { LogPrice }_{t-1}+\lambda_{2} \text { DSPD }_{t-1}+\lambda_{3} \text { AbsRet }_{t-1}+\varepsilon_{t}
$$

where, in month $t, N_{\mathrm{t}}$ is the number of public trades in the seat market, LogPrice tis $_{\mathrm{t}}$ the $(\log )$ transaction price in the seat market (midquote if there was no trade), $D S P D_{\mathrm{t}}$ is the change in the month-end quoted bid-ask spread for exchange seats, AbsRet $\mathrm{t}_{\mathrm{t}}$ is the absolute seat return, and $\varepsilon_{\mathrm{t}}$ is an error term. The model fits well (the results are not reported here) and adjusted $\mathrm{R}^{2}$ is 0.381 . As expected volume is strongly autocorrelated at short lags, and volume is negatively and significantly related to the price level and the increase in spreads. The absolute seat return in the previous month is not significant.

We then estimate the following regression model for the period from 1973 to 1994

$$
\begin{aligned}
r_{m, t}-r_{f, t}= & \alpha+\beta\left(r_{m, t-1}-r_{f, t-1}\right)+\sum_{i=1}^{3} \gamma_{i} L I Q_{t-i}+\delta_{1} B M_{t-1}+\delta_{2} D E F_{t-1}+ \\
& \delta_{3} \text { TERM }_{t-1}+\delta_{4} T B Y L D_{t-1}+\delta_{5} D I V_{t-1}+\varepsilon_{t}
\end{aligned}
$$

where, in month $t: r_{\mathrm{m}, \mathrm{t}}$ is the return on the $\mathrm{S} \& \mathrm{P} 500$ index, $r_{\mathrm{f}, \mathrm{t}}$ is the return on treasury bills; $L I Q_{t}$ is the innovation in liquidity, defined as the estimated residuals from the regression estimates of $N_{\mathrm{t}}$ in equation (4), $B M_{t}$ is the Dow Jones book-to-market ratio; $D E F_{t}$ is the low-grade bond default yield premium; TERM $M_{t}$ is the average yield of Treasury bonds with more than ten years to maturity minus the yield of T-bills that mature in three months; $T B Y L D_{t}$ is the yield of a T-bill that matures in three months; and $D I V_{t}$ is the annual dividend yield of the CRSP value-weighted index measured monthly, as described in Fama and French (1988). The last five variables are from Pontiff and Schall (1998) who describe their construction in more detail. Our model sug- 
gests a negative relation between market excess returns and lagged liquidity measures. We employ several lagged values of liquidity because we have no strong priors on the intensity of the forward-looking expectations implied in seat volumes.

\section{A.3. Results}

Table IV reports estimates of the coefficients for the 1973 to 1994 period and for two subperiods. We find evidence - consistent with Table III above - that lagged volume innovations have predictive power for future excess market returns. For the period as a whole, the coefficients on the volume innovations, $\gamma_{1}, \gamma_{2}$ and $\gamma_{3}$ are all negative and significant at the 5 percent level. The observed relation is consistent with an increase in the expected risk premium following an increase in perceived volatility, manifested by less activity in the seat market (Merton (1980)). Given that empirical evidence for Merton's model is mixed, there may be other explanations for this result. For example, liquidity in the seat market might be positively related to overall market liquidity, and hence higher asset values and lower expected returns as in Amihud and Mendelson (1986) and Chordia, Roll, and Subrahmanyam (1998). The coefficient estimates and significance levels for the five additional variables are comparable to those reported by Pontiff and Schall (1998) for the 1959 to 1994 period (see their Table 3, Panel B).

We performed several robustness checks of these results. Interestingly, the exclusion of the additional ex ante observable variables does not materially impact the estimated coefficients, or the significance, of the seat variables. The results are also relatively insensitive to the specification of equation (4). In both sub-periods (January 1973 to December 1984 and January 1985 to July 1994), the coefficients $\gamma_{1}, \gamma_{2}$ and $\gamma_{3}$ on the liquidity measures are negative, but significance levels vary, possibly a result of lack of power. In the most recent period, $\gamma_{1}$ is negative and significant at the 5 percent level, and in the older period, both $\gamma_{2}$ and $\gamma_{3}$ are negative and significant at the 10 percent level. By contrast, the significance (and sometimes the sign) of the predetermined observable variables varies in the subperiods.

\section{A.4. Other Variables: Spreads and Seat Returns}

The model suggests that other proxies for seat market liquidity such as the bid-ask spread for seats are positively related to future stock market returns. We replicate the analysis above using the bid-ask spread immediately preceding the last trade of the month as our (inverse) measure of liquidity. Although we find that the hypothesized relation does hold, significance levels vary and are sensitive to the definition of the spread. This may reflect the difficulty in 
measuring true or effective spreads. As the example in Table I shows, negotiation through successive quote revisions makes the definition of the average monthly spread problematic. Further, there can be large differences between the mean spread, median spread, beginning spread, ending spread, and pre-trade bid-ask spread in a given month. By contrast, the definition of seat market volume is unambiguous and is unlikely to be measured with error.

The only previous study of seat return dynamics (Schwert (1977a)) failed to detect any predictability in returns using seat prices in the period from 1926 to 1972. It is interesting to see if these findings hold true in our long and short-horizon data. However, using the same approach as above, we fail to demonstrate any evidence of predictability at the monthly level. Similar results are obtained using annual data from 1869 to 1998. Finally, we also estimate regressions using monthly data where the dependent variable is volume growth and independent variables are lagged values of volume innovations, seat returns, market returns, and other predicting variables. These findings confirm Schwert's original results with different data. As our model demonstrates, the failure to find predictability using seat returns is not especially surprising because seat returns need not be related to expectations of overall stock market volatility in a monotonic way. Indeed, as Table III shows, although trading frequency and volatility are significantly and positively correlated, seat returns exhibit negative but insignificant correlation.

\section{B. Transaction-Level Analysis}

Our transaction-level data allow us to ask whether seat transactions are perceived as having information content. This question is interesting because it might explain why order flow is significantly and positively correlated with contemporaneous stock market returns, as in Table III, providing an additional reason for why seat market transactions might be informative. Accordingly, we compute the permanent and temporary price movements associated with seat transactions. These definitions are common in the block trading literature. Following Keim and Madhavan (1996) we define the permanent (information-based) and temporary (liquidity-based) impacts as, respectively:

$$
\begin{aligned}
& P E R M=\ln \left(P^{P R E}\right)-\ln \left(P^{P O S T}\right) \\
& \text { TEMP }=\ln \left(P^{P O S T}\right)-\ln (P)
\end{aligned}
$$

where $P^{\mathrm{PRE}}$ is the midquote prevailing immediately before the trade, $P^{\mathrm{POST}}$ is the average of the bid and ask price prevailing just before the subsequent trade, and $P$ is the trade price itself. The permanent impact captures the long-run change in asset values as a result of a trade while the 
temporary (liquidity-based) component is interpreted as the price movement necessary to compensate the liquidity provider for accommodating the initiator's desire for immediacy. The percentage price impact of the trade is the sum of the permanent and temporary impacts. Our detailed transaction level data allows us to compute these measures for buys and sells.

These measures presume that the pre-trade reference price is an accurate assessment of the asset's underlying value or "unperturbed" price prior to the transaction. For a thinly traded asset such as an exchange seat, the pre-trade price might be a biased measure of this value if bid and offer quotes are stale. For example, consider a sell trade following a decline in the overall stock market. If the quotes are stale, the reference (pre-trade) price will be too high, and the permanent impact will be overstated. Although stale quotes represent a potentially serious problem, note that most transactions occur on days where there have been several quote revisions. Indeed, there are approximately three quote revisions just prior to a trade. Nevertheless, as a robustness check, we compute the percentage movement in the S\&P 500 from the time of the previous trade to the current trade for buys and sells.

We estimate the two components of trade impact separately for the 344 buys and 286 sells in our sample, excluding 55 uncategorized transactions. The average permanent impact for buys is 2.55 percent and for sells is -2.43 percent, and both are statistically significant. Interestingly, buy (sell) trades are associated with positive (negative) S\&P 500 movements, but these changes ( 0.82 percent for buys and -0.38 percent for sells) are not large compared to the impacts. Thus, even though there is a tendency for trade-initiation to be correlated with market movements, the transaction price is still permanently revised in the direction of trade initiation. This is consistent with there being information content to trade initiation, possibly because some brokers have information about their own order flows and hence private signals regarding future trading activity.

The estimates of the temporary component are also economically significant, but are smaller in magnitude. Temporary impacts are higher for sells $(-2.24$ percent) than buys (1.47 percent). The reason for this asymmetry is unclear. It is possible that sells occur more often in downward markets when the brokerage sector is distressed and potential buyers can extract greater rents from sellers. There are no systematic patterns in the permanent or temporary impacts for unclassified trades. In summary, the fact that seat price movements contain a perma- 
nent price component indicates that market participants revise their beliefs in response to trades, i.e., trades are perceived to contain information about future asset values.

\section{Seat Prices and Market Sentiment \\ C.1. Historical Seat Prices: 1869 to 1998}

Although seats behave as capital assets there are times when seat prices react in exaggerated ways to news events. Since seats are in limited supply and cannot easily be short sold, we are more likely to observe a bubble in these assets. Such bubbles, if they exist, may presage or occur contemporaneously with bubbles in other assets, including financial assets. It is perhaps for this reason that seat prices - like the prices of art objects - are often regarded as indicators of market sentiment.

While this argument is plausible, empirical tests are difficult to construct because of the isolated nature of such events. Nonetheless, some insights can be gained by studying the past history of seat prices. Figure 1 plots an annual nominal and real seat price index (with 1869=1)

over the entire period from 1869 to 1998 during which seats were traded. ${ }^{15}$ The nominal series exhibits three significant price run-ups - with peaks in 1929, 1969, and 1987 - that were quickly followed by declines of comparable magnitudes.

In real terms, however, even the recent highs in seat prices pale in comparison to past seat prices. Figure 1 also shows an inflation-adjusted seat price index series. 16 The real series is dominated by the 1929 observation, which is on the order of three times the magnitude of the next highest observation in 1969. In comparison, the 1987 and 1998 observations appear small, lower even than the observations at the beginning of the century. So in real terms, the capitalized value of the floor trading franchise is at approximately the same level that prevailed at the beginning of the century. These findings are consistent with an asset price bubble in the seat market that paralleled the extreme valuations in the stock market in 1929. We turn now to a more detailed investigation of seat price behavior in 1987 using the transaction level data.

\section{C.2. Seat Prices in October 1987}

Seat prices reached a record high just before the crash of October 19, 1987, much as they had just prior to the 1929 crash. To examine whether seat returns prior to the crash are in some sense abnormally large, perhaps indicative of over-optimism, we examine the returns to NYSE seats relative to the expected seat returns. Let $A R_{\mathrm{t}}$ denote the abnormal return in month $t$, defined as the residual in equation (3), and let $C A R_{\mathrm{t}}$ denote the standardized cumulative abnormal return. 
Figure 2 plots $C A R_{\mathrm{t}}$ over the period from January 2, 1986 to December 31, 1988. There is a large and statistically significant increase in the cumulative abnormal returns prior to the crash, followed by negative abnormal returns during the nine-month post-crash period. By October 1988 the cumulative abnormal returns are essentially zero.

The abnormal increase in seat prices in the 12 months prior to the crash is consistent with an exaggerated and speculative response to expected market movements by market participants. It is interesting to note that the stock market highs in 1999 are accompanied by (prior to discussions of demutualization of the NYSE in mid-1999) the highest recorded price for a NYSE seat of \$2.6 million on March 1, 1999. Perhaps for these reasons, seat prices are regarded as measures of market sentiment. 


\section{Conclusions}

Stock exchange seats are capital assets whose prices reflect the expectations of market professionals regarding future activity in the equity market as a whole. For this reason, there is considerable interest in seat transactions and prices by both practitioners and academicians. But what information, if any, is provided by transactions and quotes for stock exchange seats? This paper examines this question using: (1) Annual prices of NYSE seats over the entire history of trading from 1869 to 1998, and (2) The complete record of all bids, offers, and trades in the NYSE seat market from 1973 to 1994.

Our analysis yields several new results. Like Schwert (1977a), there is no evidence that seat returns can forecast future market volatility, volume, or stock market returns. However, lagged innovations in seat market activity are useful in predicting the monthly excess returns of the S\&P500. This is consistent with a model where an increase in seat market activity (liquidity) is associated with less volatility and hence (Merton, 1980) a lower expected risk premium.

Given that empirical evidence for Merton's model is mixed (Scruggs, 1998), it is worth noting that there may be other explanations for our findings. For example, liquidity in the seat market might be positively related to overall market liquidity, implying (Amihud and Mendelson, 1986) lower expected returns. It is worth emphasizing that seat variables are not a proxy for other variables (e.g., dividend yields, default premia, book/market ratios) that have been found to display predictive power.

We find additional confirmation for the view that market participants regard seat trades as informative in that seat transactions contain a significant permanent (information) component. Seat returns are determined like those of other capital assets. However, there is some evidence consistent with seat prices serving as measures of sentiment. Specifically, we document abnormally large run-ups in seat prices prior to October 1987 (similar to those prior to the Crash of 1929) that are subsequently reversed, consistent with an asset price bubble.

In conclusion, seat prices do indeed contain important information about the beliefs of traders regarding future stock market activity, but that this information is subtle and complex in nature. 


\section{References}

Amihud, Yakov, and Haim Mendelson, 1986, Asset pricing and the bid-ask spread, Journal of Financial Economics 17, 223-249.

Arnold, Thomas, Phillip Hersch, J. Harold Mulherin, and Jeffrey Netter, 1999, Merging markets, Journal of Finance 54, 1083-1107.

Bagnoli, Mark, and Robert Battalio, 1996, CBOT membership prices and the value of specialization: Theory and evidence, 1982-86, Working paper, Indiana University.

Campbell, John Y., 1987, Stock returns and the term structure, Journal of Financial Economics $18,373-400$.

Chiang, Raymond, Gerald Gay, and Robert Kolb, 1987, Commodity exchange seat prices, Review of Futures Markets 6, 1-10.

Chordia, Tarun, Richard Roll, and Avanidhar Subrahmanyam, 1998, Commonality in liquidity, Working paper, University of California Los Angeles.

Doede, Robert W., 1967, The monopoly power of the New York Stock Exchange, Unpublished Dissertation, University of Chicago.

Fama, Eugene, and G. William Schwert, 1977, Asset returns and inflation, Journal of Financial Economics 77, 115-146.

Fama, Eugene, and Kenneth R. French, 1988, Dividend yields and expected stock returns, Journal of Financial Economics 22, 3-25.

Fama, Eugene, and Kenneth R. French, 1993, Common risk factors in the returns on stocks and bonds, Journal of Financial Economics 33, 3-56.

Harvey, Campbell, 1991, The world price of covariance risk, Journal of Finance 46, 111-157.

Ip, Greg, and Deborah Lohse, 1998, Nasdaq plan with AMEX set for vote, The Wall Street Journal, March 18, C1.

Jarrell, Gregory A., 1984, Change at the exchange: The causes and effects of deregulation, Journal of Law and Economics 27, 273-312.

Keim, Donald B., and Ananth Madhavan, 1996, The upstairs market for large-block trades: Analysis and measurement of price effects, Review of Financial Studies 9, 1-36, 1996. 
Keim, Donald B., and Ananth Madhavan, 1997, Transactions costs and investment style: An inter-exchange analysis of institutional equity trades, Journal of Financial Economics 46, 265-292.

Keim, Donald B., and Robert F. Stambaugh, 1986, Predicting returns in the stock and bond markets, Journal of Financial Economics 17, 357-390.

Kothari, S. P., and Jay Shanken, 1997, Book-to-market, dividend yield, and expected market returns: A time series analysis, Journal of Financial Economics 44, 169-203.

McGee, Susan, 1998, Stocks are in stratosphere, by some measures, The Wall Street Journal, March 4, C1.

Merton, Robert C., 1980, On estimating the expected return on the market: An exploratory investigation, Journal of Financial Economics 8, 323-361.

Pontiff, Jeffery, and Lawrence D. Schall, 1998, Book-to-market ratios as predictors of stock returns, Journal of Financial Economics 49, 141-160.

Roeder, David, 1999, CSE seats become a hot commodity, Chicago Sun-Times, February 18, 1999, Fin, Pg. 46.

Schwert, G. William, 1977a, Stock exchange seats as capital assets, Journal of Financial Economics 4, 51-78.

Schwert, G. William, 1977b, Public regulation of national securities exchanges: A test of the capture hypothesis, Bell Journal of Economics 8, 128-150.

Schwert, G. William, 1989, Why does stock market volatility change over time, Journal of Finance 44, 1115-1154.

Schwert, G. William, 1990, Indexes of U.S. stock prices from 1802 to 1987, Journal of Business 63, 399-426.

Scruggs, John T., 1998, Resolving the puzzling intertemporal relation between the market risk premium and conditional market variance: A two-factor approach, Journal of Finance $53,575-604$.

Siegel, Jeremy, 1992, The equity premium: Stock and bond returns since 1802, Financial Analysts Journal 48, 28-38.

Stoll, Hans, 1979, Regulation of securities markets: An examination of the effects of increased competition, Monograph Series in Finance and Economics, New York University. 
Working, Holbrook, 1960, Note on the correlation of first differences of averages in a random chain, Econometrica 28, 916-918. 


\section{Table I}

\section{Sample Chronological Record of Bids, Offers, and Trades in the NYSE Seat Market}

The table reports sample quotation records for the NYSE seat market (using data obtained from the NYSE) for Monday, July 21, to Wednesday, July 23, 1986. Each record shows the prevailing bid, offer, or trade price (with the identities of the traders A, B, G, L, T, W, and $\mathrm{S}$ ) at the time of the transaction or change in quotes. The symbol $\rightarrow$ indicates the direction of a transaction. All prices are in thousands of dollars.

\begin{tabular}{lccccccc}
\hline Date & Time & Price & Identity & Price & Identity & Price & Type \\
\hline Monday, 7/21/86 & Open & $\$ 505$ & S & $\$ 600$ & W & & \\
\hline \multirow{2}{*}{ Tuesday, 7/22/86 } & Open & 505 & S & 600 & W & & Sell (T $\rightarrow$ S) \\
& $11: 15$ & & & & & & \\
& $12: 00$ & 410 & G & 600 & W & & \\
& $13: 00$ & 430 & G & 600 & W & & \\
& $13: 30$ & 430 & G & 550 & L & & \\
& $14: 25$ & 435 & B & 550 & L & & \\
Wednesday, 7/23/86 & Open & 435 & B & 550 & L & & \\
& $10: 40$ & 450 & A & 550 & L & & \\
& $12: 19$ & 460 & B & 550 & L & \\
\hline
\end{tabular}




\section{Table II}

\section{Return and Risk of NYSE Seats Using Monthly Data 1973-1994}

The table presents estimates of the regression model:

$$
R_{t}-r_{f, t}=\alpha+\sum_{i=0}^{k} \beta_{i}\left(r_{m, t-i}-r_{f, t-i}\right)+\sum_{i=0}^{k} \gamma_{i} S M B_{t-i}+\sum_{i=0}^{k} \delta_{i} H M L_{t-i}+\sum_{i=0}^{k} \phi_{i} V O L_{t-i}+\varepsilon_{t}
$$

for the period 1973-1994 and for two subperiods, where $R_{\mathrm{t}}$ is the return on NYSE seats in month $t, r_{\mathrm{ft}}$ is the treasury bill rate, $r_{\mathrm{m}, \mathrm{t}}$ is the total return on the $\mathrm{S} \& \mathrm{P} 500$ index, $S M B_{\mathrm{t}}$ is a monthly size premium (small stock return - large stock return), $H M L_{\mathrm{t}}$ is a monthly book/market premium (high $\mathrm{B} / \mathrm{M}$ return - low $\mathrm{B} / \mathrm{M}$ return), $V O L_{\mathrm{t}}$ is the growth in the aggregate NYSE share volume from month $t-1$ to month $t$, and $\varepsilon_{\mathrm{t}}$ is the error term. The first three factors are those used by Fama and French (1993). Results are presented for one lag $(k=1)$ of all variables but are similar for higher lag structures. Standard errors are in parentheses.

\begin{tabular}{|c|c|c|c|c|c|c|c|c|c|c|}
\hline \multirow[b]{2}{*}{ Period } & \multicolumn{10}{|c|}{ Estimated Regression Parameters (Standard Errors) } \\
\hline & Intercept & $r_{m, t}-r_{f, t}$ & $r_{m, t-1}-r_{f, t-1}$ & $S M B_{\mathrm{t}}$ & $S M B_{\mathrm{t}-1}$ & $H M L_{\mathrm{t}}$ & $H M L_{\mathrm{t}-1}$ & $V O L_{\mathrm{t}}$ & $V O L_{\mathrm{t}-1}$ & $\begin{array}{l}\text { Adj } R^{2} \\
\{\text { No. Obs }\}\end{array}$ \\
\hline 1/73-7/94 & $\begin{array}{c}0.004 \\
(0.008)\end{array}$ & $\begin{array}{l}0.372 * \\
(0.199)\end{array}$ & $\begin{array}{c}0.286 \\
(0.202)\end{array}$ & $\begin{array}{l}0.918 * * \\
(0.299)\end{array}$ & $\begin{array}{l}0.470 * \\
(0.281)\end{array}$ & $\begin{array}{l}-0.011 \\
(0.347)\end{array}$ & $\begin{array}{l}-0.152 \\
(0.340)\end{array}$ & $\begin{array}{c}0.103 * * \\
(0.052)\end{array}$ & $\begin{array}{c}0.068 \\
(0.053)\end{array}$ & $\begin{array}{l}0.133 \\
\{231\}\end{array}$ \\
\hline 1/85-7/94 & $\begin{array}{c}0.002 \\
(0.010)\end{array}$ & $\begin{array}{c}0.548 * * \\
(0.251)\end{array}$ & $\begin{array}{c}0.313 \\
(0.265)\end{array}$ & $\begin{array}{c}0.675 \\
(0.453)\end{array}$ & $\begin{array}{l}-0.160 \\
(0.423)\end{array}$ & $\begin{array}{l}0.957 * \\
(0.507)\end{array}$ & $\begin{array}{c}-0.940 * \\
(0.499)\end{array}$ & $\begin{array}{c}0.100 \\
(0.073)\end{array}$ & $\begin{array}{c}0.124 \\
(0.075)\end{array}$ & $\begin{array}{l}0.139 \\
\{114\}\end{array}$ \\
\hline 1/73-12/84 & $\begin{array}{l}-0.001 \\
(0.014)\end{array}$ & $\begin{array}{c}0.312 \\
(0.336)\end{array}$ & $\begin{array}{c}0.199 \\
(0.332)\end{array}$ & $\begin{array}{c}1.556 * * \\
(0.434)\end{array}$ & $\begin{array}{l}0.793 * \\
(0.416)\end{array}$ & $\begin{array}{l}-0.452 \\
(0.510)\end{array}$ & $\begin{array}{c}0.164 \\
(0.492)\end{array}$ & $\begin{array}{c}0.107 \\
(0.080)\end{array}$ & $\begin{array}{c}0.028 \\
(0.079)\end{array}$ & $\begin{array}{l}0.141 \\
\{116\}\end{array}$ \\
\hline
\end{tabular}

\footnotetext{
* denotes significance at the 10 percent level; ** denotes significance at the 5 percent level.
} 


\section{Table III \\ Correlation Matrix Using Monthly Data 1973-1994}

The table displays estimated Pearson correlation coefficients using monthly data for the period from January 1973 to July 1994 . The variables are defined (for month $t$ ) as follows: $r_{\mathrm{m}, \mathrm{t}}-r_{\mathrm{f}, \mathrm{t}}$ is the return on the $\mathrm{S} \& \mathrm{P} 500$ index less the return on treasury bills; $R_{\mathrm{t}}-r_{\mathrm{ft}}$ is the excess return on seats, $S_{t}$ is defined as the average bid-ask spread (expressed as a percentage of the midquote price) for seats, $N_{\mathrm{t}}$ is the number of transaction (volume) in the seat market, and $X_{t}=\sum_{i=1}^{N_{t}} z_{i, t}$ is the total signed volume in the seat market, where $z_{\mathrm{i}, t}$ is a tradeinitiation variable for trade $i$ in month $t(z=+1$ for a buyer-initiated trade, $z=-1$ for a seller initiated trade, and $z=0$ for a trade at the midquote. Tests of significance are based on a difference in absolute value from zero.

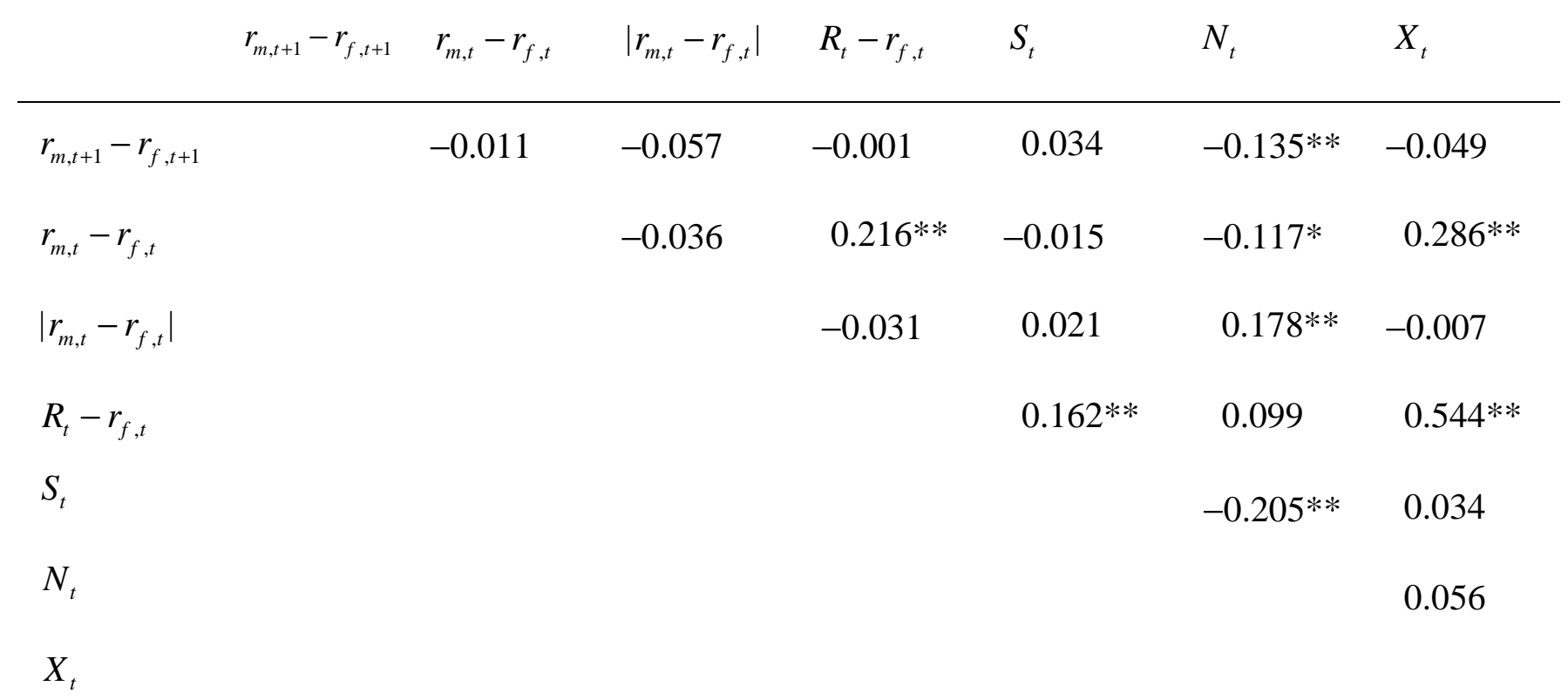

* denotes significance at the 10 percent level; ** denotes significance at the 5 percent level. 


\section{Table IV \\ Predictability of Stock Market Returns Using Monthly Data 1973-1994}

The table presents estimates of the regression model for the period 1973-1994 and for two ten-year subperiods:

$$
r_{m, t}=\alpha+\beta\left(r_{m, t-1}-r_{f, t-1}\right)+\sum_{i=1}^{3} \gamma_{i} L I Q_{t-i}+\delta_{1} B M_{t-1}+\delta_{2} D E F_{t-1}+\delta_{3} T E R M_{t-1}+\delta_{4} T B Y L D_{t-1}+\delta_{5} D I V_{t-1}+\varepsilon_{t}
$$

where, for month $t: r_{\mathrm{m}, \mathrm{t}}-r_{\mathrm{f}, \mathrm{t}}$ is the return on the S\&P 500 index less the return on treasury bills; $L I Q_{t}$ is defined as the residual from a regression of seat volumes on lagged volumes and other explanatory variables $\left(\times 10^{-2}\right), B M_{t}$ is the Dow Jones book-to-market ratio; $D E F_{t}$ is the low-grade bond default yield premium; TERM $M_{t}$ is the average yield of Treasury bonds with more than ten years to maturity minus the yield of T-bills that mature in three months; $T B Y L D_{t}$ is the yield of a T-bill that matures in three months; and $D I V_{t}$ is the annual dividend yield of the CRSP value-weighted index measured monthly, as described in Fama and French (1988). The last five variables are from Pontiff and Schall (1998) who describe their construction in more detail. Standard errors are in parentheses.

\begin{tabular}{|c|c|c|c|c|c|c|c|c|c|c|c|}
\hline \multirow[b]{2}{*}{ Period } & \multicolumn{11}{|c|}{ Estimated Regression Parameters (Standard Errors) } \\
\hline & Intercept & $r_{m, t-1}-r_{f, t-1}$ & $L I Q_{t-1}$ & $L I Q_{t-2}$ & $L I Q_{t-3}$ & $B M_{t-1}$ & $D E F_{t-1}$ & $T E R M_{t-1}$ & $T B Y L D_{t-1}$ & $D I V_{t-1}$ & $\begin{array}{c}\text { Adj. } R^{2} \\
\{\text { No. Obs }\}\end{array}$ \\
\hline 1/73-7/94 & $\begin{array}{c}-0.085^{* *} \\
(0.023)\end{array}$ & $\begin{array}{l}-0.079 \\
(0.066)\end{array}$ & $\begin{array}{c}-0.287 * * \\
(0.143)\end{array}$ & $\begin{array}{c}-0.309 * * \\
(0.142)\end{array}$ & $\begin{array}{c}-0.309 * * \\
(0.141)\end{array}$ & $\begin{array}{c}-13.570 * * \\
(3.126)\end{array}$ & $\begin{array}{l}2.833 * * \\
(1.054)\end{array}$ & $\begin{array}{l}-0.301 \\
(0.335)\end{array}$ & $\begin{array}{c}-0.997 * * \\
(0.241)\end{array}$ & $\begin{array}{l}5.917 * * \\
(1.124)\end{array}$ & $\begin{array}{l}0.155 \\
\{223\}\end{array}$ \\
\hline 1/85-7/94 & $\begin{array}{l}-0.026 \\
(0.050)\end{array}$ & $\begin{array}{c}0.018 \\
(0.103)\end{array}$ & $\begin{array}{c}-0.593 * * \\
(0.291)\end{array}$ & $\begin{array}{c}-0.084 \\
(0.282)\end{array}$ & $\begin{array}{c}-0.309 \\
(0.141)\end{array}$ & $\begin{array}{l}20.989 * * \\
(9.469)\end{array}$ & $\begin{array}{c}-1.260 \\
(2.847)\end{array}$ & $\begin{array}{c}-3.177 * * \\
(0.915)\end{array}$ & $\begin{array}{c}-3.719 * * \\
(0.824)\end{array}$ & $\begin{array}{l}7.391 * * \\
(2.232)\end{array}$ & $\begin{array}{l}0.157 \\
\{111\}\end{array}$ \\
\hline 1/73-12/84 & $\begin{array}{c}-0.096 * * \\
(0.034)\end{array}$ & $\begin{array}{c}-0.168^{*} \\
(0.096)\end{array}$ & $\begin{array}{l}-0.179 \\
(0.185)\end{array}$ & $\begin{array}{c}-0.307 * \\
(0.182)\end{array}$ & $\begin{array}{c}-0.358 * \\
(0.183)\end{array}$ & $\begin{array}{c}-17.529 \\
(11.322)\end{array}$ & $\begin{array}{l}3.549 * * \\
(1.283)\end{array}$ & $\begin{array}{l}-0.637 \\
(0.612)\end{array}$ & $\begin{array}{c}-0.953 * * \\
(0.332)\end{array}$ & $\begin{array}{l}6.751 * * \\
(2.668)\end{array}$ & $\begin{array}{l}0.215 \\
\{108\}\end{array}$ \\
\hline
\end{tabular}

$*$ denotes significance at the 10 percent level; ** denotes significance at the 5 percent level. 


\section{Legend for Figure 1:}

The figure shows average annual real and nominal seat prices in the period from the start of exchange seat trading in 1869 until discussions of demutualization in 1998. Prices are normalized to equal one in 1869.

\section{Legend for Figure 2:}

This graph shows the cumulative standardized abnormal returns to NYSE seats in the period from January 1986 to December 1988 surrounding the Crash of October 1987. Abnormal returns are computed as the residuals from the model of seat excess returns estimated in Table II. 


\section{Notes}

${ }^{1}$ Roeder (1999) observes "There's is a new kind of bull market at the Chicago Stock Exchange and, if history is a guide, it might serve as a warning for investors... Only twice has the value of a Chicago Stock Exchange membership exceeded \$100,000. Both occurrences came weeks before the two worst crashes in stock market history - in the Octobers of 1929 and 1987." Similarly, the Los Angeles Times of May 22, 1998 (Section D, Page 4) notes that "the price for a seat on the New York Stock Exchange fell Thursday for the third time in a row-the first time that has happened in seven years-but brokers said the drop was a fallout from the NYSE's recent trading scandal, not an early warning that the stock market is about to dive." (Emphasis added.) McGee (1998) discusses seat prices as measures of sentiment.

${ }^{2}$ As the NYSE notes, "Prices are based on the interplay of supply and demand and reflect the profitability of the brokerage business, the level of trading volume on the Exchange, general economic conditions, and other factors."

${ }^{3}$ Alternatively, we could interpret $\sigma$ as an inverse proxy for an overall stock market liquidity factor. A decrease in expected liquidity increases the transactions costs of traders who in turn demand a higher risk premium.

${ }^{4}$ For simplicity, we assume a new entrant does not sell his/her seat until his/her type is revealed.

${ }^{5}$ In theory, since seats can be leased, a synthetic short could be constructed. However, in practice this appears difficult given the nature of leasing relationships, as discussed in Section II below.

${ }^{6}$ Seat and NYSE membership are synonymous because until 1871 members sat in assigned chairs during the roll call of stocks.

${ }^{7}$ Originally, there were 1,060 seats but this number was increased to 1,375 in 1932 and finally to the present number of 1,366 in 1953. In addition, there are a small number of "partial" memberships that convey limited physical or electronic access to the floor for a basic fee supplemented by annual fees.

${ }^{8}$ We thank Steve Fuller of the NYSE for providing access to these data. 
${ }^{9}$ Due to omissions in the data obtained from the NYSE, we are missing quote and price information for two blocks of time: January 1980 to December 1980 and May 1983 to October 1983.

${ }^{10}$ Market returns are measured using a value-weighted index of NYSE stocks constructed by Schwert (1990) for the 1870 to 1925 period and by CRSP for the 1926 to 1998 period.

${ }^{11}$ By July 1994, the value of a $\$ 1$ seat investment was $\$ 4.36$ versus $\$ 9.55$ for the S\&P 500 index. Seats also exhibited considerably more volatility - the standard deviation of monthly seat returns over the 1973 to 1994 period of 12.41 percent versus 4.59 percent for the S\&P 500 return.

${ }^{12}$ We thank Gene Fama and Ken French for generously providing these data.

13 See Schwert (1989) for a discussion of time variation in volatility.

14 We thank Jeff Pontiff and Larry Schall for generously providing these data.

${ }^{15}$ We do not "split-adjust" the seat prices for the increase in the number of seats in 1932 and 1952 because we view these events as analogous to a secondary equity issue rather than a straight dilution of existing equity. Since the magnitude of the increases are relatively small, however, our conclusions are unaffected by such an adjustment.

${ }^{16}$ We thank Jeremy Siegel for providing us with the data. See Siegel (1992) for further details. 